quatro propostas para o "Verão e Projecto", destinadas a estudantes do $9^{\circ}$ ao $11^{\circ}$ anos de escolaridade. O desafio lançado teve uma aceitação muito boa, com a inscrição e frequência dos projectos ("A electroquímica é...", "A Química: uma ciência sem fronteiras", "Química em acção", "Química no NanoMundo") por cento e sessenta e cinco jovens, durante uma semana, de 27 de Junho a 22 de Julho de 2011.

Integrada nas actividades da U.Jr., teve ainda lugar no DQB, de 4 a 8 de Julho de 2011, a 5 a Escola de Química da Universidade do Porto, dirigida a estudantes dos $10^{\circ}$ e $11^{\circ}$ anos do Ensino Secundário, de elevado nível, para evidenciar oportunidades actuais em Química e apostas no futuro. A Escola de Química 2011 proporcionou um estágio a quinze jovens, provenientes de diferentes concelhos do País, cada um dos quais participou no desenvolvimento de um projecto científico em curso no DQB, integrado na respectiva equipa de investigação. No último dia da Escola, decorreu, com grande sucesso, um Seminário, em que cada um dos formandos apresentou uma comunicação, permitindo uma divulgação das actividades científicas desenvolvidas globalmente. A adesão dos membros do DQB (professores, investigadores, estudantes de mestrado e de doutoramento) ao acompanhamento destes jovens foi grande, mas o retorno foi mais compensador, pois a postura destes investigadores juniores, a sua criatividade e o seu interesse pela inovação, superaram tudo o que seria de esperar. Todos os representantes dos órgãos académicos convidados (Reitor Prof. Marques dos Santos, vice-Reitor Prof. António Marques, Director da FCUP, Presidentes dos Conselhos Científico e Pedagógico da FCUP, Secretário Geral da SPQ) estiveram presentes nas sessões de abertura e/ou encerramento desta Escola de Química, dando um forte sinal do reconhecimento conferido à importância do evento na promoção desta área da ciência.

Ao longo de 2011, a Universidade do Porto está a comemorar uma efeméride de grande simbolismo: o centenário da sua fundação. A FCUP é, desde a sua formação, em 1911, também há um século, a Escola desta Universidade responsável pelo Ensino das Ciências Exactas e Naturais, continuando a ser responsável por graduação em áreas das Ciências Exactas e Naturais, em que a Química se inclui. Foi também em 1911 que Ferreira da Silva, professor de Química na Academia Politécnica do Porto, se tornou director dessa mesma academia e o primeiro presidente da Sociedade Portuguesa de Química. Antecedendo o início das comemorações do centenário da Universidade do Porto, esteve patente em Novembro e Dezembro de 2010, no actual edifício da Reitoria da UP (instalações da FCUP desde a sua fundação até à sua mudança para as novas instalações), a exposição "Ferreira da Silva: o Homem, o Professor, o Cientista". Esta exposição, comissariada por Carlos Corrêa, professor de
Química da UP, reuniu obras e aparelhos científicos utilizados por Ferreira da Silva, pertences ao espólio do Museu da Ciência da Faculdade de Ciências, e constituiu o ponto alto da homenagem que a universidade dedicou ao histórico químico e académico português.

No dia 23 de Setembro de 2011 teve lugar a Noite da Química no espaço do Átrio de Química do antigo edifício da FCUP. O evento foi promovido pela SPQ, a nível nacional, e a adesão pelo público, no Porto, foi extraordinária, ultrapassando todas as nossas expectativas.

De 15 de Outubro a 15 de Novembro de 2011, a Sala de Exposições do DQB abriu as suas portas com uma exposição sobre Marie Curie à qual se seguiu, a 9 de Dezembro, uma palestra sobre a mesma prémio Nobel da Química, cuja distinção perfaz, também este ano, o centenário da sua atribuição.

Para finalizar este registo, refere-se a festa de encerramento do AIQ, a 15 de Dezembro de 2011, na qual foi lançado um selo comemorativo, por iniciativa do DQB, que deixará aos vindouros uma marca do Ano Internacional da Química.

\section{Maria das Dores Ribeiro da Silva} (mdsilva@fc.up.pt)

Docente do Departamento de Química e Bioquímica da FCUP

\title{
Acácia Mimosa - A Essência de uma Praga
}

As diversas espécies da acácia-mimosa são exóticas em Portugal, sendo actualmente consideradas invasoras. Tal acontece porque são plantas pirófitas, as suas sementes são estimuladas pelo calor do fogo e germinam rapidamente. Por outro lado, têm uma enorme capacidade para se multiplicarem vegetativamente.

Com o objectivo de ajudar a resolver este problema ambiental, e no âmbito do Ano Internacional da Química, desenvolvemos este projeto que pretende divulgar possíveis formas de explorar este recurso de modo a que seja útil ao nosso país, transformando uma praga em mais-valias. Para tal, contámos com os conhecimentos de Química e suas aplicações. Com este projecto mostrámos que a Química, nas mãos de jovens interventivos e construtivos, pode ajudar a encontrar respostas para muitos problemas.

\section{Descrição das Actividades}

Este projecto teve como objectivos divulgar a Investigação Científica e aplicar conhecimentos de Química e Física a situações do quotidiano.

Começámos por nos debruçar sobre a extracção do óleo essencial da flor, pois sabemos que é utilizado na produção de perfumes e outros cosméticos de elevada qualidade. Entretanto, apercebemo-nos de que as aplicações da acácia-mimosa não se limitam à indústria dos cosméticos, ela tem também muitas potencialidades em diversas indústrias químicas tais como: produção de tintas e corantes; a extracção de goma-arábica, muito uti- 
lizada na produção de medicamentos, de vinho e colas; a extração da celulose, para produção de pasta de papel;

\section{Bancada 1: A Química na Arte} Produção de tintas à base de corantes, da flor da mimosa (amarelo), da folha (verde) e do carvão (preto).

Os veículos testados foram: clara de ovo, gema de ovo, óleo de linhaça, cola de madeira...

Bancada 2: A química na Indústria Têxtil

Os alunos tingiram tecidos de algodão.

Bancada 3: A Química na Indústria da Pasta de Papel

Extracção da fibra de celulose para produzir pasta de papel. a produção de contraplacados; a utilização como biomassa, entre outras.
No Laboratório de Química os alunos realizaram as seguintes experiências:
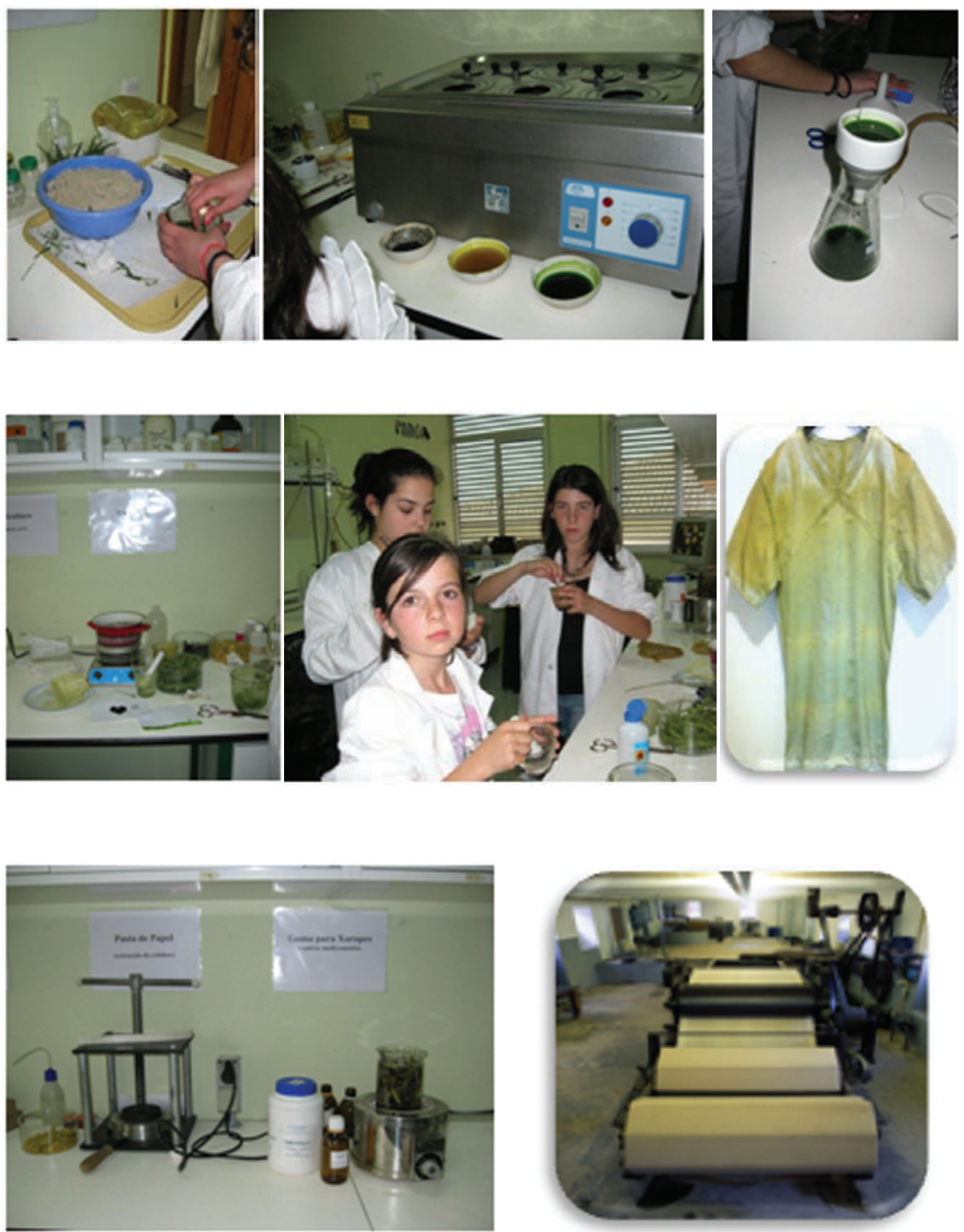

Bancada 4: A Química na Indústria

\section{Farmacêutica}

Extracção da goma, goma-arábica, da casca da Acácia para produção de xaropes e outros medicamentos.
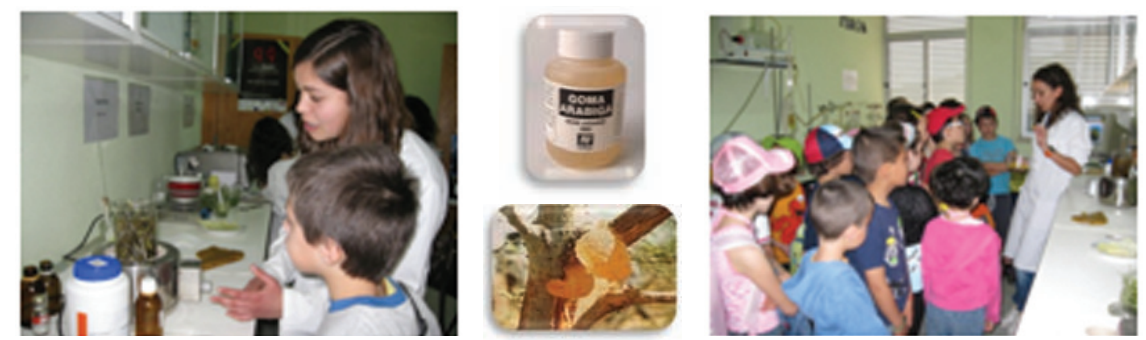

Bancada 5: A Química e a Biotecnologia

Apicultura - produção de cera e mel, de excelente qualidade.
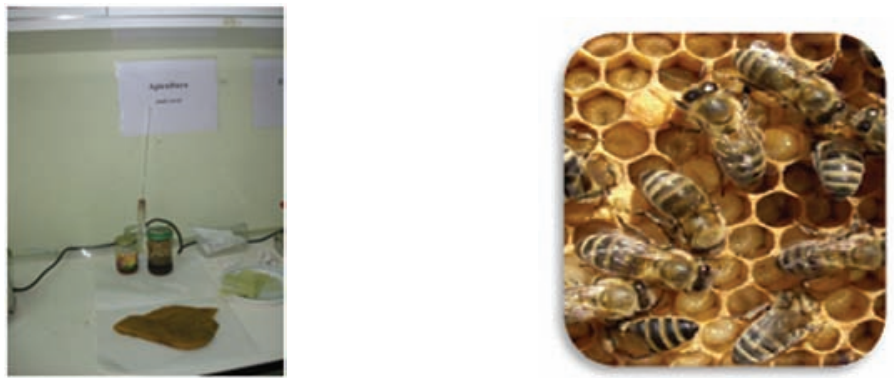
Bancada 6: A Química e os Materiais

Produção de contraplacado.

Utilização da madeira para mobiliário, postes, construção naval...
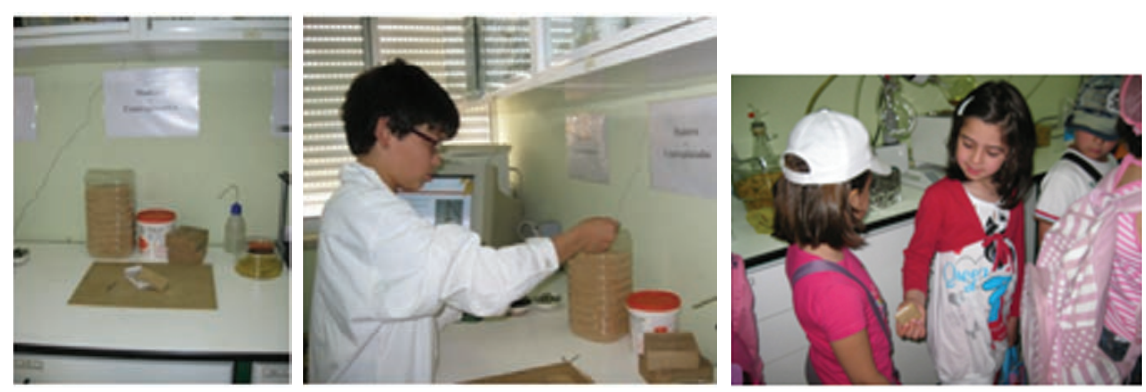

Bancada 7: A Química na Produção de Energia (Biomassa)

A combustão, reacção exotérmica.
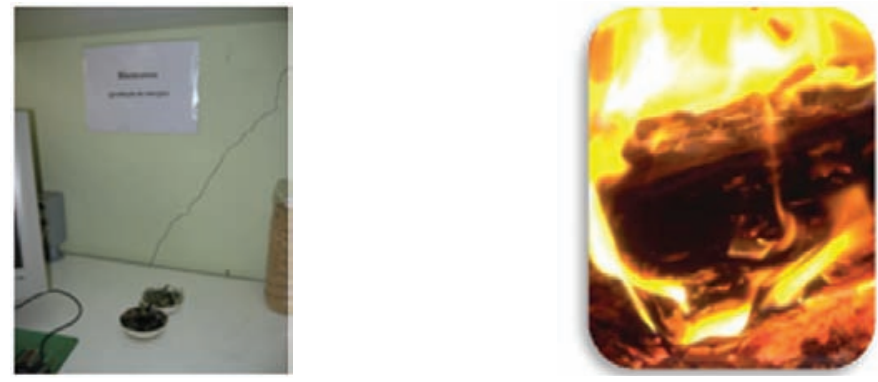

Bancada 8: A Química na Indústria dos Perfumes e outros Cosméticos Extracção do óleo essencial da flor, por várias técnicas.

Destilação por arrastamento de vapor, extracção por solvente (extractor de Soxhlet), destilação a pressão reduzida, enfleurage ou enfloração.
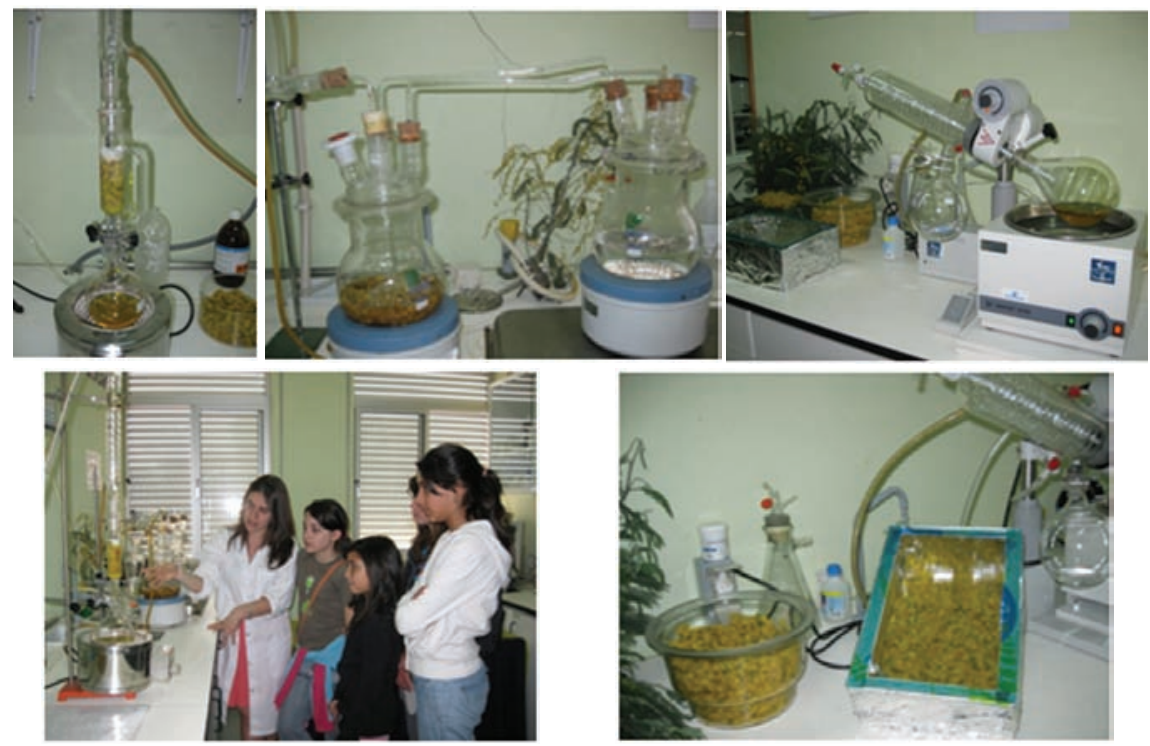

Bancada 9: A Decoração de Espaços

Construção de coroas de ramos de Acácias.
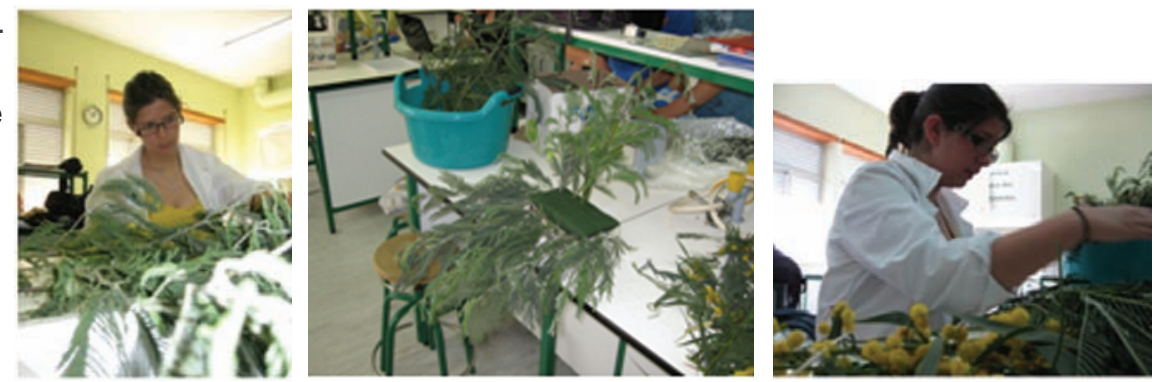

Ana Vaz Pinto e Pedro Vaz Pinto

Alunos do 11. B, 10.A e 7.o A

(pvazp@sapo.pt)

Instituto D. João V, Louriçal 